\title{
Theoretical Comparison Between (XI \& C) Cores of Homopolar Linear Synchronous Motor
}

\author{
مقارنة نظرية بين قلبين على شكل حرفى أكساى وسى \\ غخرلك تزامنى خطى متجانس الأقطاب
}

\section{S. A. El-Drieny}

Department of electrical engineering, Facuity of engineering EL.-Mansoura Univeristy, El-Mansoura, Egypt

\begin{abstract}
ملخثى البيحث

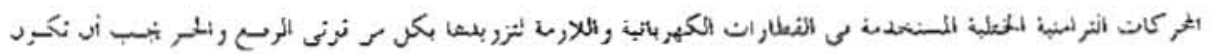

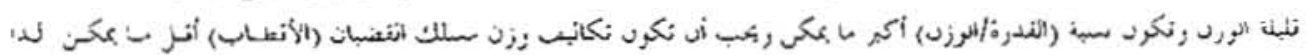

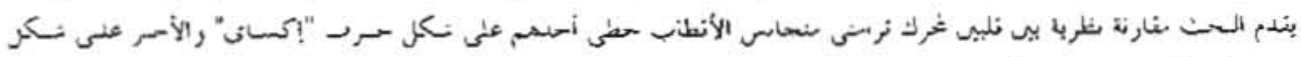

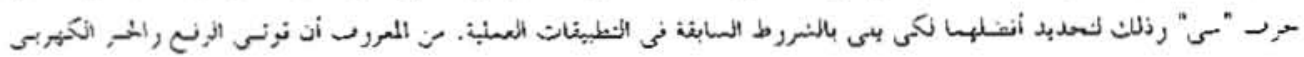

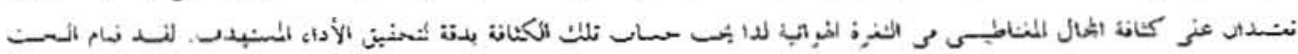

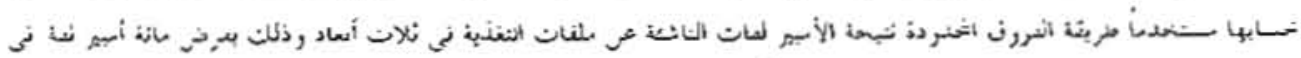

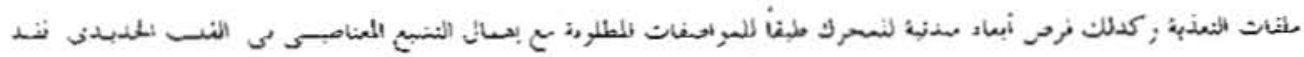

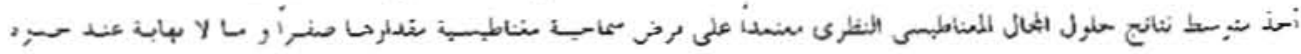

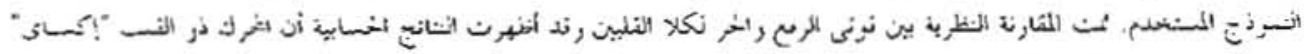

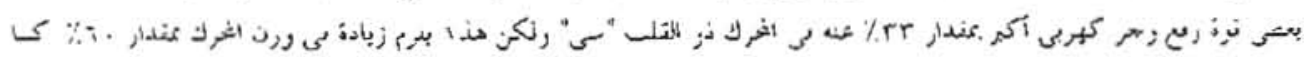

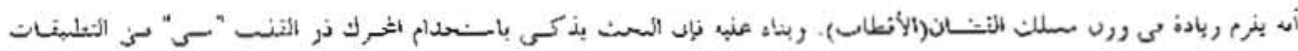

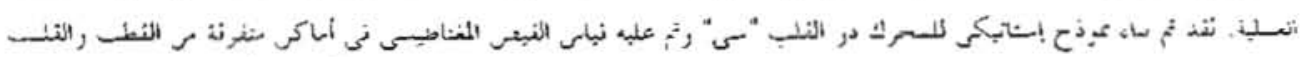

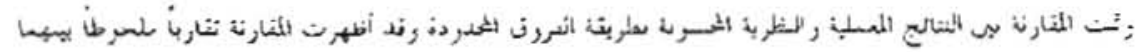

\section{Abstract}

This paper presents the theoretical comparison between two different geometries for the core of homopolar linear synchronous motor HiLSM. The theoretical analysis estimated the airgap lux density, the attraction and traction forces This anatysis is based on a magnetic field study using 3-dimensional finite difference method FDM of scalar magnetic potential. The average resuits of zero and infinite permeabiitity boundanes is consıdered. The flux per pole, under a c. limbs either in " $\mathrm{C}$ " or in "XI" core is taken for obtaining the majority of nomal force. Results reveai that the "Xl" core shape was the optimum form because it provides higher both of traction and attraction forces than " $\mathrm{C}$ " core. But, the extra iron required 
and attraction forces than "C" core. But, the extra iron required and the cost of rast track poles were the weak points for unchoosing this form in practica! application. An experimental investigation is carried out on laboratory static prototype motor LSPM of "C" core HLSM to verify the theoretical results. It is shown that the experimental and computed results are in good agreement.

\section{Introduction}

Linear motors with transverse magnetic circuit providing both traction and attraction torces were introduced in 1974 [1]. A recent addition to this form of linear moiors is "XI" core type [2] and it is shown in figure (1). This geometry evolved by addition of two extra uron limbs to enclose the primary windings overhang of " $\mathrm{C}$ " core geomemy as shown in figure (2).

Usuaily problems associated with applications of linear motors in urban transport vehicles $[8,11]$ are

1).The exact traction force should be matched with the correct attraction force at all times of the duty cycle. Hence the correct airgap flux density which meets the traction and attraction force requirements should be investigated.

2) The (power/weight) ratio of linear motor must be high as much as possible

3) The cost of rail track poles should be minimum.

Accordingly, this paper presents a theoretical comparison between two cores "XI" core and "C" core for HISM to choose which one is able to satisfy the above requirements. The comparison is based on the analysis of magnetostatic potential arising from d.c. excitation using 3-dinensional finite ditference method FDM[3]. The slotted effect of atmature core and the rron saturation are neglected in theoretical calculations. Once, the airgap flux density is obtained, the traction and attraction forces can easily be estimated[4]

\section{Field Computation:}

The volume of either "C-core" or "XI-core" homopolar linear synchronous motor (HLSM) is enclosed in 3 -dimensional region as shown in Fig. (3) this is seen to extend $10 \mathrm{~cm}$ beyond the iron surface. The 3-dimensional region can be formulated in differential form of scalar magnetic potential $\boldsymbol{P}$ as follows:

region doesn't contain a source (current free region)

$\frac{d^{2} p}{d x^{2}}+\frac{d^{2} p}{d y^{2}}+\frac{d^{2} p}{d z^{2}}=0$

Considenng filling up this region with a set of unitormly spaced nodes of spacing unt length. Fig.(4) shows a cubic element fion a large mesh contannng 6 nodes Each of six element connected to any node is taken to have umt permeance 
unless an iron boundary is less than $1 \mathrm{~cm}$ distance when the reluctance is iroportionally lessi.

The network, which containing all nodes, is solved by representing it in a omputer program and applying a technique known as successive over relaxation S.O.R) method [5]. Relaxation of a network consısts of treatıng all nodes in equence but one node at a time. Taking the example of figure (4), the node equation s simply based on Kirchoff's current law :-

$3_{1}+P_{2}+P_{3}+P_{4}+P_{5}+P_{6}-6 P_{0}=0$

If the left hand side of this equation is evaluated for an arbitrary choice of node rotentials a quantity not equal to zero will most likely result. This is called a "residual" and is proportional to the total flux converging on the central node. For a atısfactory solution the residual at all nodes should, for successive iteration, be very mall compared with the flux passing through any one element (they shouid ideally be ero). The node potentials are obtamed when the computer program has achieved invergence to a highest residual of a magnitude less than $10^{-4}$.

The computer results are hold in a large array of magnetostatic potentials in 3limensional specifying potential for pole pitch of $H L S M$ at $\mathrm{l} \mathrm{cm}$ intervals. This is the nost suitable form for permanent file storage. It is possible by simple steps to compute he armature flux and the pole flux distribution from the magnetic potential and the rermeance of elements of the mesh. Each branch of (Finite Difference Method) D.M. Is associated with a flow quantity carried between two points at either end of he branch. This is directly related to the flux in the magnetic field. The flow, :quivalent to the flux, in each branch, is calculated from the potential difference icross the branch.

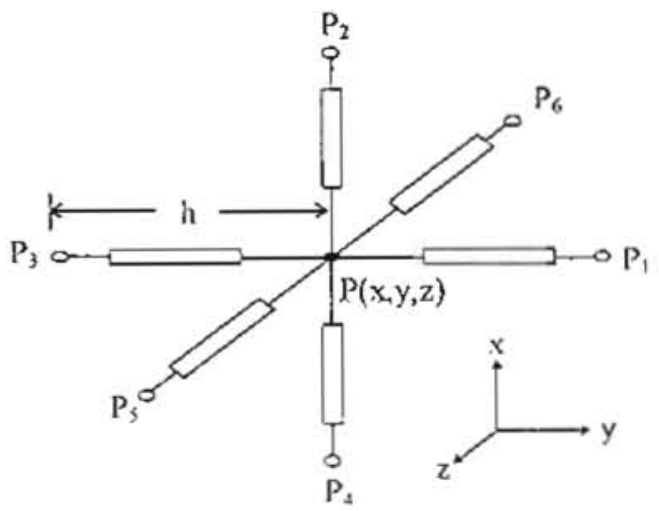

Fig (4) : Electrical analogue of single node 
i.e.

Branch flux $\phi=\left(\frac{\mu_{0} h^{2}}{L}\right)\left(P_{1}-P_{2}\right)$

where $L$ is the brancb length $P_{1}$ and $P_{2}$ are the branch potential and $\frac{\mu_{0} h^{2}}{L}$ is the permeance (PM). The branches have possible directions, hence the fluxes are the individual flux components un 3-dimensions. The calculations are normalized for simplicity taking the basic mesh. as one unit $(\mathrm{L}=1)$ and working with a nomual excitation of 100 AT. followings:

The fluxes are calculated taking $\mu=l$ and $h=l$ to give normalized units as Firstly, in case of " $\mathrm{C}$ " core

left hand-core flux

$\phi_{A}=P M\left[\sum_{x=1, y=y_{1}}^{x=1+P P=y_{1}+c w}\left[P\left(x, y, z_{s+1}\right)-P\left(x, y, z_{s}\right)\right]\right]$

Right hand core flux:

$\phi_{B}=P M\left[\sum_{x=1, y=y_{3}}^{x=1+p y_{1}=y_{i}+\operatorname{tar}}\left[P\left(x, y, z_{s+1}\right)\right]-P\left(x, y, z_{s}\right)\right]$

Secondly; in case of "XI" core

Left hand side outer core flux $\phi_{c}$

$\phi_{c}=P M\left[\sum_{r=1, y=y_{c}}^{x=1+p p y_{1} y_{1}+o w} p\left(x, y, z_{s+1}\right)-p\left(x, y, z_{s}\right)\right]$

Left side outer core flux $\phi_{\mathrm{A}}$

$\dot{\phi}_{.1}=P M\left[\sum_{x=1 . y=y,}^{x=1+p p, y=y_{i}+\cdots \mathfrak{} v} p\left(x, y, z_{s+1}\right)-p\left(x, y, z_{s}\right)\right]$

Right hand side outer core flux $\phi_{B}$

$\phi_{B}=P M\left[\sum_{\substack{x=1, y=y, x=1+p p, y=v,+c w}} p\left(x, y, z_{s+1}\right)-p\left(x, y, z_{s}\right)\right]$

Right hand side outer core flux $\phi_{D}$

$\phi_{D}=P M\left[\sum_{\mathrm{x}=1, \mathrm{y}=\mathrm{y}_{\mathrm{f}}}^{x=1+p p y=y_{\mathrm{s}}+o w} p\left(x, y, z_{s+1}\right)-\rho\left(x, y, z_{s}\right)\right]$ 
where -

PM: Permeance.

$P$. Node potential.

cw Rught \& left (a.c. windings) core width.

ow Right \& left outer core width.

Zs Surface of armature core level.

PP Pole pitch.

in case of HLSM a full pitch region is considered, and the interfaces with adjacent regıons $(\mathrm{a}, \mathrm{b})$ are treated as zero permeability boundaries gıving a "Positıve mirror image" field on the remote side of the boundary. The remaining boundaries $(c, d, e, f)$ taking, for first solution as zero permeability and for second solution the permeability assumed to be infintty, then taken the average of both the first, and the second solution [6]. The HSLM iron core and track-pole assumed to have infinite permeability and not to be saturated. Also the effect of open slots is neglected.

\section{Adjustment of track-pole potential :}

The pole of the HSLM is a block of iron whose potential is not known at the start of the finite difference solution. Its potential must be derived as the solution proceeds to converge, but an estumate of say 20 units may speed the initial calculations. For a singie block of iron the derivation of the biock potential is a simple extension of the relaxation process. The block is simply treated as a guant node withun the mesh and is relaxed in the following way:

The total flux entering the block is calculated by summing the contributions from " $n$ " nodes connected to the block. The result is the block residual $R_{B}$, see Fig. (5).

$$
\mathrm{R}_{\mathrm{B}}=\sum_{r=1}^{n}\left(P_{r}-P_{o}\right) S_{r}
$$

where $S_{\text {r }}$ is the permeance of the $r^{\text {th }}$ element. The amount of potential adjustment $\Delta P_{0}$ required to reduce the block residual to zero is derived from the equation

$$
\sum_{r=1}^{n}\left[P_{r}-\left(P_{o}+\Delta P_{o}\right)\right] S_{r}=0
$$

i.e.

$$
\Delta P_{v}=\frac{\sum_{r=1}^{n}\left(P_{r}-P_{o}\right) S_{r}}{\sum_{r=1}^{n} S_{r}}
$$




$$
\Delta P_{o}=\frac{R_{B}}{S_{B}}
$$

If all branches connected to the block have unit permeance the block residual is given by :

$$
\mathrm{R}_{\mathrm{B}}=\sum_{r=1}^{\prime \prime}\left(P_{r}-P_{o}\right)
$$

And $\mathrm{S}_{\mathrm{B}}$, the characteristics permeance of the block, is given by :-

$$
S_{B}=n
$$

The block residual is not evaluated in a single stage as a node residual would be. Instead, for the nodes inside the block, the residual is calculated if there are nodes in free space, but instead of being relaxed, the residual is added to a cumulative sum to form the block residual, $R_{B}$. . This residual is used at thie end of each set of iterations to calculate the block potential adjustment. The value of $R_{B}$ denved in this way would be slightly different to that derived by evaluating the flux contributions to the block at the end of individual iterations since node values next to the block are being relaxed one at a time and are therefore being changed while the block residual calculation is in progress.

The validity of the technique is, of course, not in question sunce the same conditions for convergence apply but the rate of convergence may be altered. It is possible to use an acceleration factor (relaxation factor) in changing the block potential and one is used to obtain the current solutions. By the above technique the potential of the block is readjusted and all nodes within it get the new potential $\mathrm{P}_{0}$.

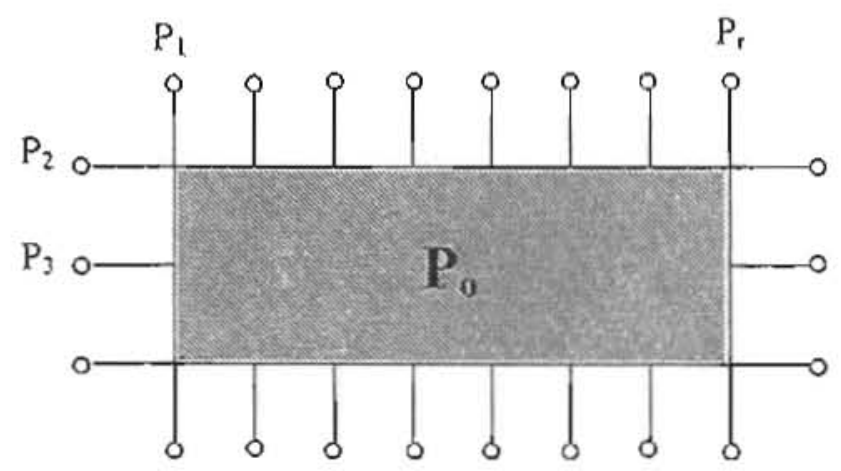

Figure (5) Relaxation of a single block. 


\section{Normal Force Calculation:}

the nomal force is greatly influenced by the d.c. excitation $\mathrm{m}$.m.f. which varıes considerably with operating conditions. For a given (track) pole shape and stator dimensions the special distribution of magnetic scalar potential is calculated for 100 Ampere turns for d.c. excitation coil. The flux per pole and the peak flux density due to 100 AT then can be calculated. Normal force and thrust are calculated from the Maxwell stresses derived from the fieid of net potentials. When the fieid equation solved numerically it is often convenient to determine the forces by surface integration of Maxwell's second stress tensor [7], in air, over any surface enclosing the part on which the force is produced. The stresses consist of a tension along the lines of force, $\frac{1}{2} \mu_{0} \mathrm{H}^{2}$, and an equal pressure at right angles to them. Resolving in the normal and tangential directions relative to arbitrarily chosen surface as shown in Fig. (6), the component of the stress directed away from the surface is

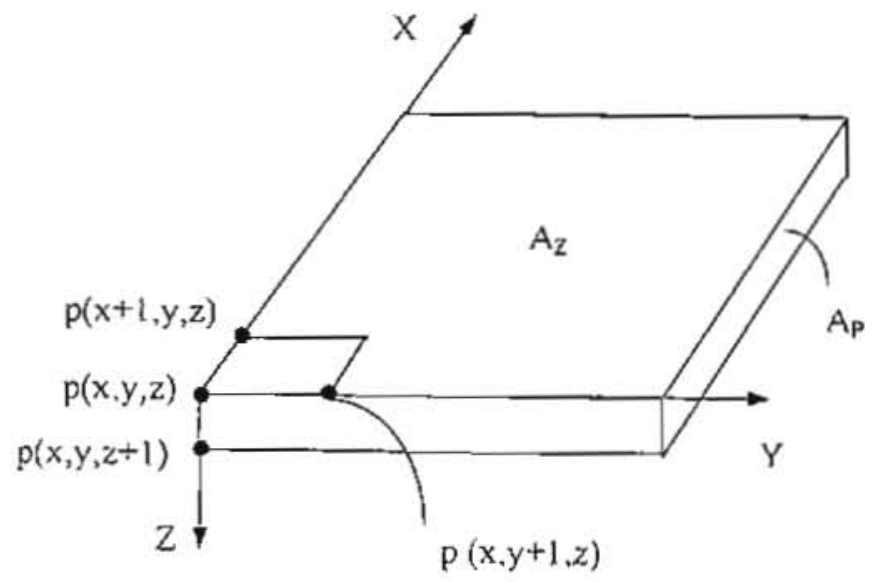

Fig. (6) Surface of integration to calculate tangential \& normal stresses

$F_{n}=\frac{1}{2} \mu_{o}\left(H_{n}^{2}-H_{t}^{2}\right)$

and the tangential stress is

$F_{t}=\mu_{o} H_{n} H_{t}$

where, 


$$
\begin{aligned}
& H_{n}=H_{z}=\sum_{\substack{x=1 . y=h \\
x=1}}^{x=1}\left[p\left(x, y, z_{s}\right)-p\left(x, y, z_{s+1}\right)\right] \\
& H_{r}=\sum_{x=1, y=1}^{x=a, y=b} 0.5\left[p\left(x+1, y, z_{s}\right)-p\left(x, y, z_{s}\right)+p\left(x+1, y, z_{s+1}\right)-p\left(x, y, z_{s+1}\right)\right] \\
& H_{y}=\sum_{x=1, y=h}^{x=a, y=1} 0.5\left[p\left(x, y+1, z_{s}\right)-p\left(x, y, z_{s}\right)+p\left(x, y+1, z_{s+1}\right)-p\left(x, y, z_{s+1}\right)\right] \\
& H_{1}^{2}=H_{x}^{2}+H_{y}^{2}
\end{aligned}
$$

Thrust $=\sum A_{z} F_{t}$

Normal force $=\frac{1}{2} \mu_{o}\left[\sum A_{z} H_{n}^{2}-\sum A_{p}\left(H_{x}^{2}+H_{y}^{2}\right)\right]$

This approach is written into a computer subroutine which calculate the thrust, normal force per pole for 100 AT excitation.

\section{$\underline{5 . D i s c u s s i o n}$ of computed and laboratory results :}

A prototype laboratory static motor (PLSM) with "C" core is constructed from laminations with open slots, and used d.c. excitation coils only $[9,10]$. The air-gap is heid at $1 \mathrm{~cm}$ and the d.c. coil is excited with the d.c. supply avallable. The armature Plux is measured using a search coil and flux meter. The comparison between the computer predicted armature flux values with those measured on (PLSM) is shown in table (1). The remarkable point which arises from this table is that, there is a difference between the predicted values of armature flux and that obtained by experimental measurements. This is due to the effects of open slots and magnetic saturation in the iron core, which are neglected in the theoretical investigations. The comparison of magnetizing fluxes computed for $(\mathrm{C}, \mathrm{XI})$ cores at $100 \mathrm{AT}$ d.c. excitation is shown in table (2). It will be noticed from this table that the armature flux in case of (XI-core) is greater than by about $15 \%$ than the case of (C-core). Similarly; both the normal force stress and thrust force stress are greater by $33 \%$ in case of (XI-core) than in case of $\mathrm{C}$-core as shown in table (3).

Table (1): Static flux and its comparison with theory at 5A excitation field for C-core.

\begin{tabular}{|l||c||c|}
\hline & Test $\Phi(\mathrm{mwb})$ & Computation $\phi(\mathrm{mwb})$ \\
\hline \hline B: Armature flux L.H.S & 0.54 & 0.76 \\
\hline \hline C. Armature flux R.H.S & 0.55 & 0.77 \\
\hline
\end{tabular}


Table (2): Comparison of computed magnetizing fluxes for (C,XI) cores at 100AT d.c. excitation.

flux / pole (mwb)

\begin{tabular}{|l||c||c|}
\hline & $\begin{array}{c}\text { C-core } \\
\text { HLSM }\end{array}$ & $\begin{array}{c}\text { X1-core } \\
\text { HLSM }\end{array}$ \\
\hline A: Core flux L.H.S & & 0.1786 \\
\hline \hline B: Armature flux L.H.S & 0.076 & 0.089 \\
\hline C. Armature flux R.H.S & 0.077 & 0.091 \\
\hline \hline D: Core flux R.H.S & & 0.191 \\
\hline \hline E: Track flux & 0.136 & 0.16 \\
\hline
\end{tabular}

Table (3) : Comparison of computed forces for (C,XI) cores when 100At d.c. excitation.

\begin{tabular}{|l||c||c|}
\hline & C-core & XI-core \\
\hline Normal force stress $\mathrm{N} / \mathrm{m}^{2}$ & 8.5 & 11.3 \\
\hline \hline Thrust force stress $\mathrm{N} / \mathrm{m}^{2}$ & 97 & 129 \\
\hline
\end{tabular}

\section{Conclusion}

The traction and attraction forces of HLSM are influenced by argap flux density which depends on the core shape. Therefore, it is important during early stage of design of such type of linear motors to study which one is able to overcome the probierns associated with practical applications for urban transport vehicles. The (power/weight) ratio has also to be in mind of the designer as well as the ratl track pole cost. For this purpose, the theoretical analysis, applying the 3-dimensional finite difference method FDM has been suggested, using the scalar magnetic potentials as the main fieid parameters. In this analysis the d.c. excitatıon has been only considered and the magnetic saturation and slotted armature are neglected. Once, the flux per pole is obtained for different core-shape $(\mathrm{XI}, \mathrm{C})$ the traction and attraction forces are easily obtained. However, computed results reveal that :

1) XI-core shape gives higher traction and attraction forces than C-core by about $33 \%$.

2) The (power/weight) ratio of XI-core motor is smaller than of $\mathrm{C}$-core motor

3) The cost of rail track poies of XI-core is higher than of C-core motor.

So, the paper spots the light on the above facts to be under the hand of the designers. Conclusively, the $\mathrm{C}$-core motor is recommended in practical application for urban transport vehucles.

Laboratory measurements which have been carried out on LSPM to measure the flux under different positions of core-shape, show a reasonable agreement with the theoretical investigation. 


\section{List of Symbols}

cw: Right and left (a.c winding) core width.

$F_{1}$ : Thrust per unit area

$F_{\mathrm{n}}$ : Normal force per unit area.

$\mathrm{n}$ : All nodes connected to the poles.

ow: Right and left outer core width .

$P$ : Scalar magnetic potential (or node potential).

$P M$ : permeance.

$P P$ : pole pitch.

$R_{B}$. The block residual.

$S_{r}$ : The permeance of the elernents which connected to the pole.

$Z_{s}$ : Surface of the armature core level.

\section{References}

[1]Eastham. J.F. and Laithwaite. E.R. "Linear induction motors as electromagnetic rivers" proc. IEE 1974,121(10) pp 1099-1108

[2]Rajanathon. C.B and Lowther. D.A. and Freeman. E.M. "Study of XI-core" transverse-flux plate levitator" proc. IEE vol 127 pt. B No. 3 May 1980 pp(183189).

[3]Balchin, M.J. and Davidson, J.A. "Numerical method for calculating magnetic flux and eddy-current distribution in three dimensions" proce. IEE., vol $127 \mathrm{pt}$. A. No. I Jan 1980.

[4]Murai. Toshaki "Characteristics of linear synchoronous motor combined propulsion, Levitation and guidance", Elect. Engg. In Japan vol. 115 No. 4 Jan 15 1995 p 134-145

[5]Stoll, R.L. "Solution of linear steady state eddy currents problems by complex successive over relaxation s.o.r" proc. [EE 1970, Vol. 117 p 1317-1323

[6]El-drieny, S. A. " A heteropolar Linear synchronous motor and levitator" $\mathrm{Ph} . \mathrm{D}$ thesis, 1981 Nottingham university Nottingham, England.

[7]Binns, K.J. and Lawrenson, P.J. "Analysis and computation of electric and magnetic fieid problems" Pergamon press ltd, $2^{\text {nd }}$ edition, 1973

[8[Eastham , J,F,Balchin,M.J. C Comparison of characteristics of heteropolar and homopolar linear synchronous motors" EE colloquium(Digest) No II(1983) publ. by EEE London.

[9] Lorenzen, Hans Werner Experimental investigation of the operating behaviour of linear synchronous motors* publ. By IEEE, USA,IEEE/PES summery meeting 1985 ЛЧ 14-19.

[10] Eastham ,J.F,Balchin, ,M.J Full-scale testing of high speed linear synchronous

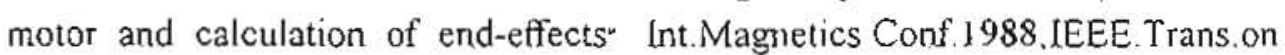
Magnetics Vol. 24,No.6, Nov. 1988, P $2892-2894$

[11] Eastham ,J.F - Novel synchronous machines, linear and disc IEE. proc. part B vol 137 No 1, Jan 1990 p 49-58. 
Fig. (1) X Y- Core homopolar linear Syncbronous Motor

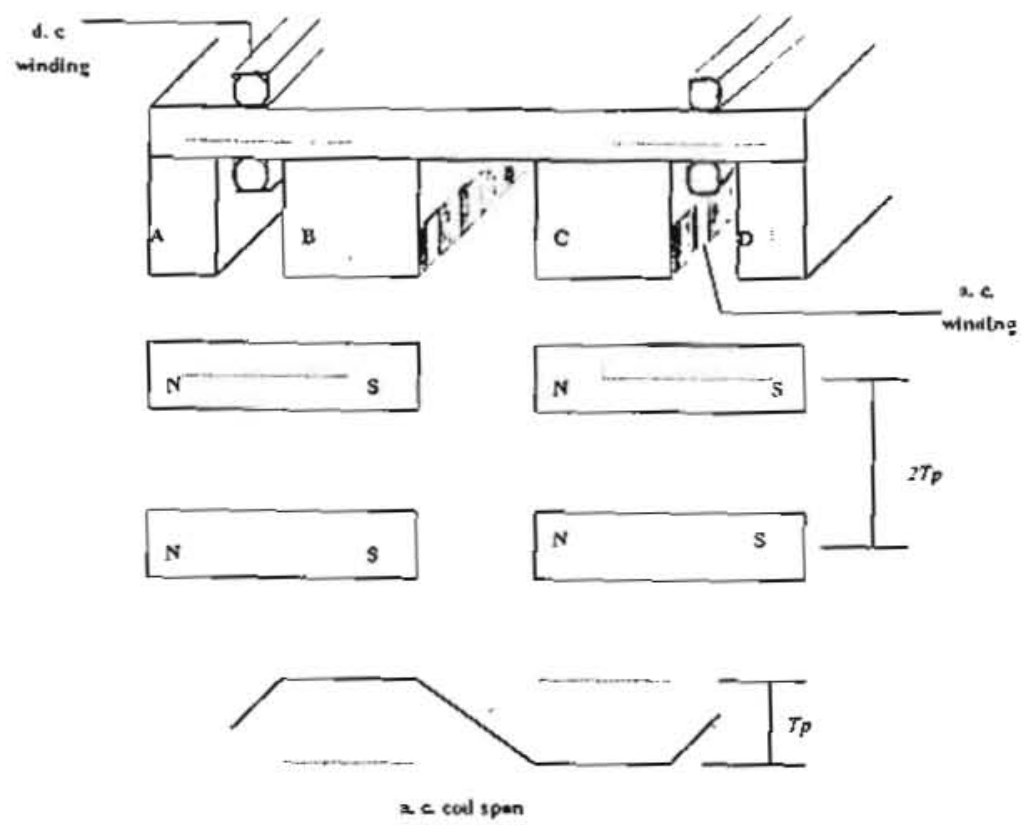

Fig. (2) C. Core bomopolar Linear Syncbronous Motor
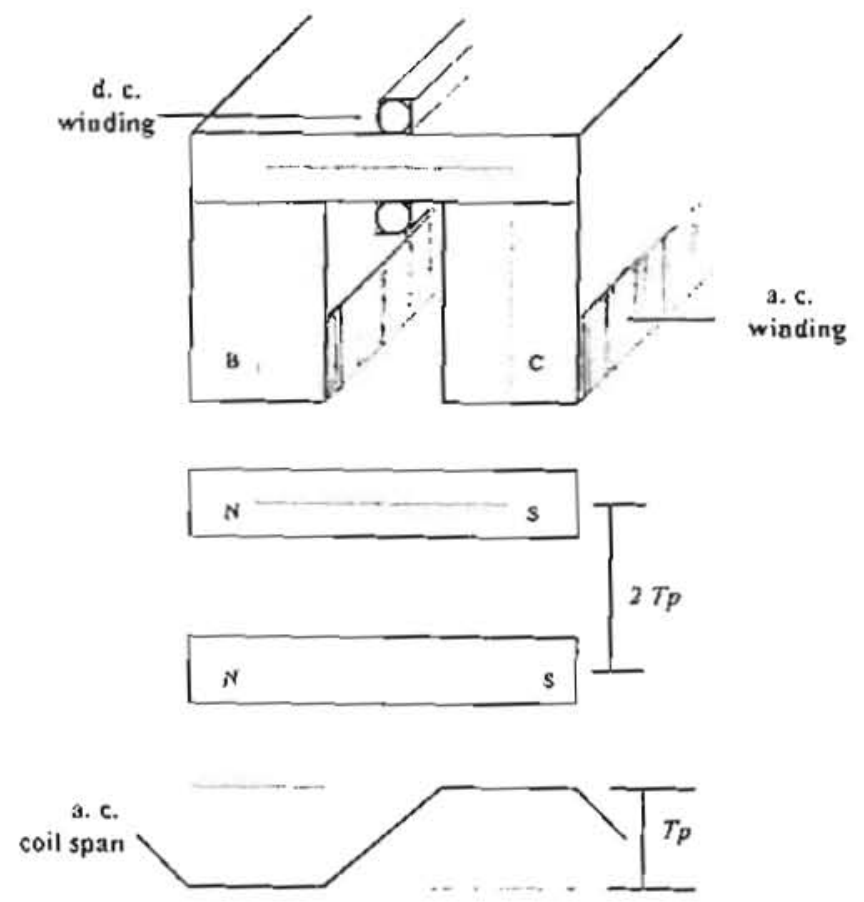

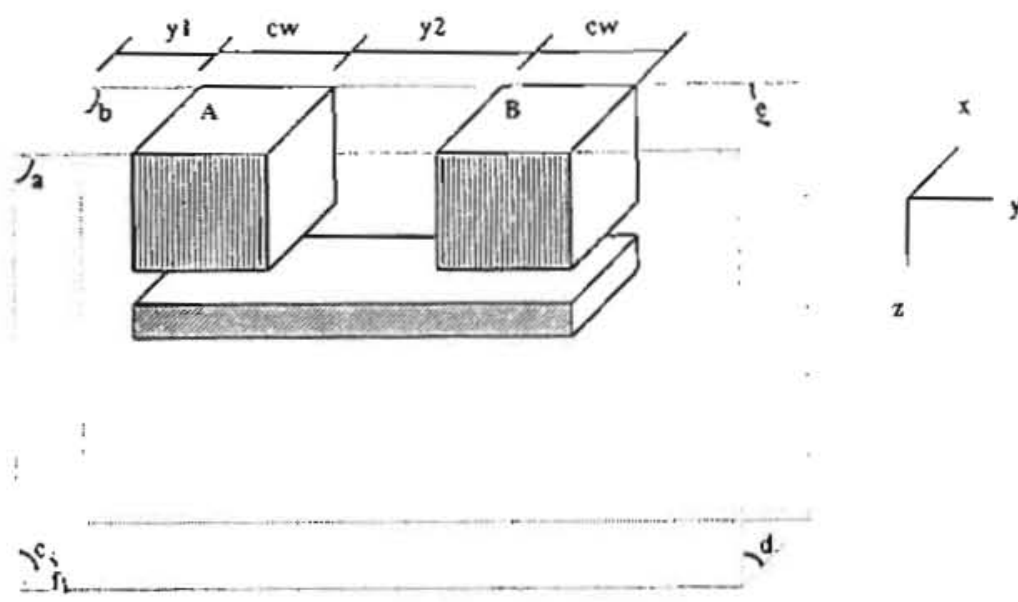

(a)
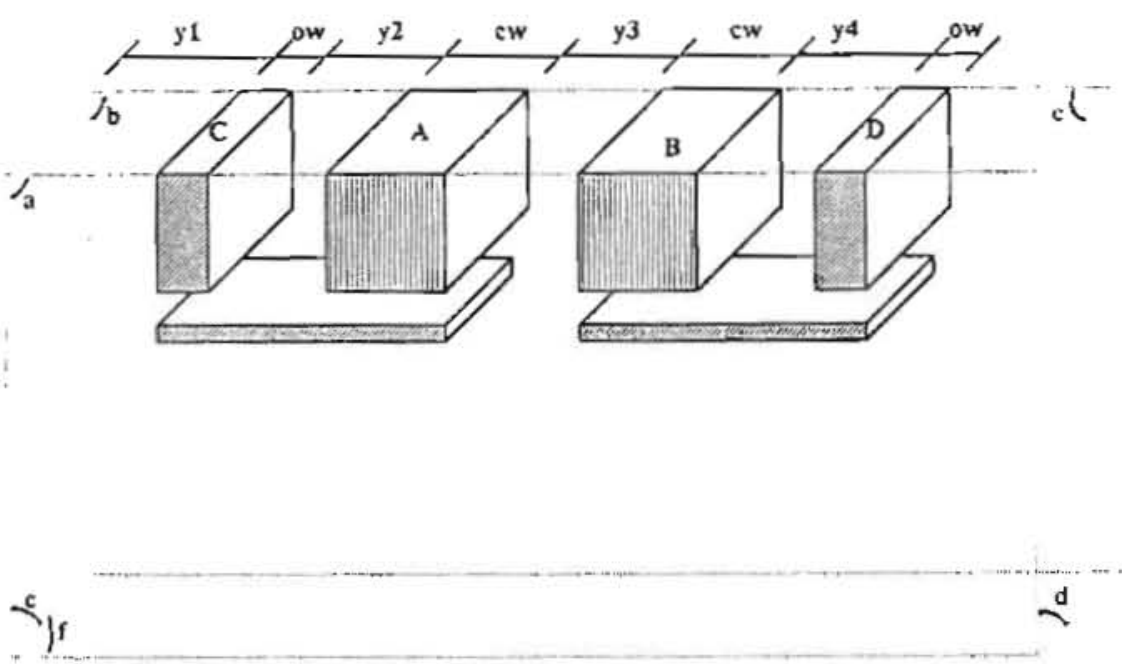

(b)

Fig (3) Three dimensions region for physical model and track pole showing mesh boundaries definition
(a) C-core
(b) $\mathrm{XI}$-core 